Article

\title{
Streamer Inception from Ultra-Sharp Needles in Mineral Oil Based Nanofluids
}

\author{
Mauricio Aljure ${ }^{1, *(1)}$, Marley Becerra ${ }^{1}$ and Mattias E. Karlsson ${ }^{2}$ \\ 1 School of Electrical Engineering and Computer Science, KTH Royal Institute of Technology, SE-100 44 \\ Stockholm, Sweden; marley@kth.se \\ 2 School of Engineering Sciences in Chemistry, Biotechnology and Health, KTH Royal Institute of Technology, \\ SE-100 44 Stockholm, Sweden; mekarls@kth.se \\ * Correspondence: maraljure@gmail.com or mauar@kth.se
}

Received: 24 July 2018; Accepted: 6 August 2018; Published: 8 August 2018

check for updates

\begin{abstract}
Positive and negative streamer inception voltages from ultra-sharp needle tips (with tip radii below $0.5 \mu \mathrm{m}$ ) are measured in $\mathrm{TiO}_{2}, \mathrm{SiO}_{2}, \mathrm{Al}_{2} \mathrm{O}_{3}, \mathrm{ZnO}$ and $\mathrm{C}_{60}$ nanofluids. The experiments are performed at several concentrations of nanoparticles dispersed in mineral oil. It is found that nanoparticles influence positive and negative streamers in different ways. $\mathrm{TiO}_{2}, \mathrm{SiO}_{2}$ and $\mathrm{Al}_{2} \mathrm{O}_{3}$ nanoparticles increase the positive streamer inception voltage only, whilst $\mathrm{ZnO}$ and $\mathrm{C}_{60}$ nanoparticles augment the streamer inception voltages in both polarities. Using these results, the main hypotheses explaining the improvement in the dielectric strength of the host oil due to the presence of nanoparticles are analyzed. It is found that the water adsorption hypothesis of nanoparticles is consistent with the increments in the reported positive streamer inception voltages. It is also shown that the hypothesis of nanoparticles reducing the electron velocity by hopping transport mechanisms fails to explain the results obtained for negative streamers. Finally, the hypothesis of nanoparticles attaching electrons according to their charging characteristics is found to be consistent with the results hereby presented on negative streamers.
\end{abstract}

Keywords: streamer inception; electric discharges; nanofluids; mineral oil

\section{Introduction}

A couple of decades ago, it was experimentally observed that some nanoparticles (NPs) improve the dielectric strength of host dielectric liquids [1]. This finding was counterintuitive to common knowledge suggesting that particles decrease the dielectric strength of any host liquid [1]. Nevertheless, subsequent experiments have confirmed the dielectric strength improvement due to the presence of some NPs added into dielectric liquids. Some overall facts have been deduced from these experimental studies. It has been concluded that smaller NPs yields better effects than larger NPs, that there is an optimal concentration of NPs, and that their effect depends on the characteristics of the liquid and the NPs [1-4].

The dielectric strength of a dielectric liquid is characterized by its electric breakdown withstand capability. In most of the literature, the dielectric strength of liquids is studied following standards such as IEC 60897 (e.g., [5-8]). However, breakdown in dielectric liquids is a highly complicated, not well understood process, involving electronic, thermal and mechanical phenomena taking place within fractions of microseconds [9-11]. For this reason, only few numerical models of pre-breakdown phenomena can be found in the literature (e.g., [12-14]), which unfortunately cannot fully explain all experimental findings [15]. Without a clear understanding of the breakdown phenomena in base oils, it is difficult to interpret and explain the effect of NPs on the breakdown phenomena. In spite of this, three main hypotheses have been postulated in the literature explaining the dielectric strength improvements of hydrocarbon oil due to the presence of NPs. They can be summarized as: (1) water 
adsorption on the NPs surface inhibits detrimental effects of moisture on dielectric strength [16], (2) NPs attach electrons converting them into slower ions [5], and (3) increments of electronic trapping and de-trapping processes due to NPs reduce the electron velocity [6].

Electric breakdown in hydrocarbon oils is the consequence of the development of so-called streamers. Hence, the study of streamers and other pre-breakdown phenomena is key to understand the effect of NPs on the electric breakdown process. It is generally accepted that negative streamers in base oils initiate from electronic avalanches in the liquid phase followed by light emission, a shock wave and the formation of a gas bubble [9-11]. The mechanism of initiation of positive streamers is nevertheless less understood [17], although it has been observed to be influenced by moisture content [18].

In general, the streamer inception has been studied for needles with tip radii larger than $0.5 \mu \mathrm{m}$ (e.g., $[17,19])$. However, it is generally difficult to theoretically interpret these experimental results since the processes of injection of charges into the liquid can only be quantified for sharper needles [17]. Considering that the self-consistent numerical simulation of injection of charges from ultra-sharp needles (with tip radii less than $0.5 \mu \mathrm{m}$ ) and its associated electrohydrodynamic liquid motion has been recently reported [20], the measurement of streamer initiation from ultra-sharp needles is the next step to enable the future physical analysis of this process using computer simulation. It also provides an interesting scenario to test whether the proposed hypotheses can explain the effect of NPs in host oil.

In this study, positive and negative streamer inception voltages of nanofluids prepared with five different kinds of NPs are investigated for ultra-sharp needles. Differences between positive and negative streamer inception voltages are highlighted and the existing hypotheses are discussed based on the reported results. The paper is organized as follows. Section 2 introduces the experimental conditions of this work. Section 3 presents the results of the experiments. The main hypothesis explaining effects of NPs are discussed in Section 4. Finally, conclusions are presented at the end of the paper.

\section{Experimental Details}

\subsection{Electrode Configuration}

Streamers are initiated in a needle-sphere electrode configuration. Since ultra-sharp needles are made using electro-etching of $1 \mathrm{~mm}$ diameter tungsten wires, their tip radius $R_{\text {tip }}$ range between $110 \mathrm{~nm}$ and $350 \mathrm{~nm}$. The tip of the needles is separated by a distance $d_{g a p}$ to stainless steel spheres with diameter of $10 \mathrm{~mm}$. The electrode configuration is placed within a $16 \mathrm{~mm}$ inner diameter container with borosilicate cylindrical glass walls, filled with the liquid under test. The experimental setup is shown in Figure 1. Since the used ultra-sharp needles are very fragile, they are often damaged by strong discharges occurring mainly at positive polarity or by handling accidents. For this reason, several needles are used throughout the experiments as reported in Table 1.

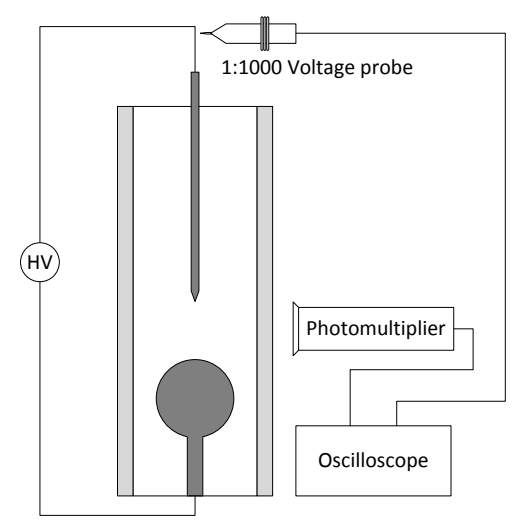

Figure 1. Experimental set up is shown. Streamers are initiated in a needle to sphere electrode configuration. A photomultiplier is used to detect the light emitted by the streamer. Both light and voltage signals are recorded with an oscilloscope. 
Table 1. Nanofluids preparation details and results of the streamer inception measurements.

\begin{tabular}{|c|c|c|c|c|c|c|c|c|c|}
\hline \multicolumn{3}{|c|}{ NF Preparation } & \multirow{2}{*}{$\begin{array}{c}\text { Electrode } \\
\text { Configuration }\end{array}$} & \multicolumn{3}{|c|}{$\begin{array}{l}\text { Weibull } \\
\text { Parameters }\end{array}$} & \multicolumn{3}{|c|}{$\begin{array}{l}\text { Streamer Inception Voltage } \\
\text { and Laplacian Electric Field }\end{array}$} \\
\hline NP & wt $\%$ & $\begin{array}{l}\text { Cluster } \\
\text { Size (nm) }\end{array}$ & & $\eta$ & $\beta$ & $\gamma$ & $\begin{array}{l}V_{50 \%} \\
\text { (V) }\end{array}$ & $\begin{array}{c}E_{L A P} \\
(\mathrm{MV} / \mathrm{cm})\end{array}$ & $\begin{array}{c}\% \\
\text { Change }\end{array}$ \\
\hline \multirow{8}{*}{$\begin{array}{c}\mathrm{ZnO} \\
\text { Size: } 20 \mathrm{~nm} \\
\text { Hydrophobic } \\
\tau<0.1 \mathrm{~ns} \\
\rho_{m}=5.6 \mathrm{~g} / \mathrm{cm}^{3}\end{array}$} & 0 & - & \multirow{4}{*}{$\begin{array}{c}\text { Negative Streamer } \\
d_{\text {gap }}=4.5 \mathrm{~mm} \\
R_{\text {tip }}=225 \mathrm{~nm}\end{array}$} & 2403 & 5.85 & 3439 & 5696 & 30.8 & - \\
\hline & 0.01 & 150 & & 5588 & 8.43 & 1761 & 7111 & 38.4 & $24.8 \%$ \\
\hline & 0.02 & 165 & & 3760 & 4.77 & 3534 & 7016 & 37.9 & $23.2 \%$ \\
\hline & 0.05 & 380 & & 5758 & 7.17 & 1686 & 7157 & 38.7 & $25.7 \%$ \\
\hline & 0 & - & \multirow{4}{*}{$\begin{array}{c}\text { Positive Streamer } \\
d_{\text {gap }}=3 \mathrm{~mm} \\
R_{\text {tip }}=200 \mathrm{~nm}\end{array}$} & 1265 & 3.92 & 4516 & 5668 & 33.4 & - \\
\hline & 0.01 & 150 & & 1183 & 3.37 & 5271 & 6331 & 37.3 & $11.7 \%$ \\
\hline & 0.02 & 165 & & 1700 & 4.00 & 5051 & 6602 & 38.9 & $16.5 \%$ \\
\hline & 0.05 & 380 & & 1168 & 2.62 & 5727 & 6743 & 39.8 & $19.0 \%$ \\
\hline \multirow{12}{*}{$\begin{array}{c}\mathrm{SiO}_{2} \\
10-20 \mathrm{~nm} \\
\text { Hydrophilic } \\
\tau \sim 30 \mathrm{~s} \\
\rho_{m}=2.6 \mathrm{~g} / \mathrm{cm}^{3}\end{array}$} & 0 & - & \multirow{6}{*}{$\begin{array}{c}\text { Negative Streamer } \\
d_{\text {gap }}=1.3 \mathrm{~mm} \\
R_{\text {tip }}=350 \mathrm{~nm}\end{array}$} & 1981 & 4.25 & 3752 & 5569 & 21.8 & - \\
\hline & 0.001 & - & & 2595 & 5.55 & 2874 & 5303 & 20.8 & $-4.8 \%$ \\
\hline & 0.002 & - & & 1972 & 4.68 & 3733 & 5557 & 21.8 & $-0.2 \%$ \\
\hline & 0.005 & - & & 1800 & 3.83 & 3782 & 5417 & 21.2 & $-2.7 \%$ \\
\hline & 0.01 & - & & 1568 & 3.12 & 4077 & 5472 & 21.4 & $-1.7 \%$ \\
\hline & 0.05 & - & & 2387 & 5.46 & 3281 & 5512 & 21.6 & $-1.0 \%$ \\
\hline & 0 & - & \multirow{6}{*}{$\begin{array}{c}\text { Positive Streamer } \\
d_{\text {gap }}=1.5 \mathrm{~mm} \\
R_{\text {tip }}=170 \mathrm{~nm}\end{array}$} & 1955 & 4.02 & 3130 & 4915 & 36.5 & - \\
\hline & 0.001 & - & & 2400 & 4.91 & 2598 & 4824 & 35.8 & $-1.8 \%$ \\
\hline & 0.002 & - & & 1080 & 2.91 & 3684 & 4636 & 34.4 & $-5.7 \%$ \\
\hline & 0.005 & - & & 1290 & 2.37 & 3764 & 4869 & 36.1 & $-0.9 \%$ \\
\hline & 0.01 & - & & 2650 & 4.90 & 3253 & 5711 & 42.4 & $16.2 \%$ \\
\hline & 0.05 & - & & 2985 & 1.53 & 4835 & 7184 & 53.3 & $46.2 \%$ \\
\hline \multirow{8}{*}{$\begin{array}{c}\mathrm{Al}_{2} \mathrm{O}_{3} \\
20 \mathrm{~nm} \\
\text { Hydrophilic } \\
\tau \sim 40 \mathrm{~s} \\
\rho_{m}=4 \mathrm{~g} / \mathrm{cm}^{3}\end{array}$} & 0 & - & \multirow{5}{*}{$\begin{array}{c}\text { Negative Streamer } \\
d_{\text {gap }}=1.3 \mathrm{~mm} \\
R_{\text {tip }}=350 \mathrm{~nm}\end{array}$} & 1294 & 2.92 & 4248 & 5390 & 21.1 & - \\
\hline & 0.005 & 270 & & 1697 & 3.61 & 4041 & 5575 & 21.8 & $3.4 \%$ \\
\hline & 0.01 & 230 & & 1895 & 3.75 & 3853 & 5571 & 21.8 & $3.4 \%$ \\
\hline & 0.02 & 325 & & 1875 & 3.08 & 4061 & 5726 & 22.4 & $6.2 \%$ \\
\hline & 0.05 & 310 & & 1858 & 3.90 & 3870 & 5561 & 21.8 & $3.2 \%$ \\
\hline & 0 & - & \multirow{3}{*}{$\begin{array}{c}\text { Positive Streamer } \\
d_{\text {gap }}=1.5 \mathrm{~mm} \\
R_{\text {tip }}=170 \mathrm{~nm}\end{array}$} & 1349 & 1.97 & 4032 & 5152 & 38.2 & - \\
\hline & 0.005 & 270 & & 1854 & 4.18 & 3763 & 5461 & 40.5 & $6.0 \%$ \\
\hline & 0.01 & 230 & & 2376 & 2.53 & 3762 & 5817 & 43.1 & $12.9 \%$ \\
\hline \multirow{8}{*}{$\begin{array}{c}\mathrm{TiO}_{2} \\
20 \mathrm{~nm} \\
\text { Hydrophilic } \\
\tau \sim 25 \mathrm{~s} \\
\rho_{m}=3.8 \mathrm{~g} / \mathrm{cm}^{3}\end{array}$} & 0 & - & \multirow{4}{*}{$\begin{array}{c}\text { Negative Streamer } \\
d_{\text {gap }}=1.38 \mathrm{~mm} \\
R_{\text {tip }}=350 \mathrm{~nm}\end{array}$} & 1085 & 1.92 & 4696 & 5592 & 21.6 & - \\
\hline & 0.001 & 270 & & 1451 & 3.09 & 4286 & 5574 & 21.5 & $-0.3 \%$ \\
\hline & 0.002 & 255 & & 972 & 1.97 & 4775 & 5582 & 21.6 & $-0.2 \%$ \\
\hline & 0.005 & 250 & & 1904 & 4.12 & 3756 & 5497 & 21.3 & $-1.7 \%$ \\
\hline & 0 & - & \multirow{4}{*}{$\begin{array}{c}\text { Positive Streamer } \\
d_{\text {gap }}=4.65 \mathrm{~mm} \\
R_{\text {tip }}=150 \mathrm{~nm}\end{array}$} & 1916 & 2.48 & 4097 & 5750 & 37.3 & - \\
\hline & 0.001 & 270 & & 2192 & 1.77 & 4730 & 6512 & 42.2 & $13.2 \%$ \\
\hline & 0.002 & 255 & & 3679 & 4.84 & 4804 & 8214 & 53.3 & $42.9 \%$ \\
\hline & 0.005 & 250 & & 2476 & 2.39 & 5834 & 7958 & 51.6 & $38.4 \%$ \\
\hline \multirow{8}{*}{$\begin{array}{c}\mathrm{C}_{60} \\
0.7 \mathrm{~nm} \\
\text { Hydrophilic } \\
1 \mathrm{ps}<\tau<50 \mathrm{~s} \\
\rho_{m}=1.65 \mathrm{~g} / \mathrm{cm}^{3}\end{array}$} & 0 & - & \multirow{4}{*}{$\begin{array}{c}\text { Negative Streamer } \\
d_{\text {gap }}=1.63 \mathrm{~mm} \\
R_{\text {tip }}=350 \mathrm{~nm}\end{array}$} & 1284 & 2.96 & 4725 & 5860 & 21.9 & - \\
\hline & 0.002 & - & & 1666 & 3.38 & 4550 & 6045 & 22.5 & $3.2 \%$ \\
\hline & 0.005 & - & & 1893 & 3.47 & 4566 & 6269 & 23.4 & $7.0 \%$ \\
\hline & 0.01 & - & & 2500 & 3.94 & 4493 & 6771 & 25.3 & $15.5 \%$ \\
\hline & 0 & - & \multirow{4}{*}{$\begin{array}{c}\text { Positive Streamer } \\
d_{g a p}=1.13 \mathrm{~mm} \\
R_{\text {tip }}=300 \mathrm{~nm}\end{array}$} & 2894 & 8.29 & 2206 & 4975 & 25.66 & - \\
\hline & 0.002 & - & & 1366 & 4.06 & 3913 & 5161 & 26.62 & $3.7 \%$ \\
\hline & 0.005 & - & & 1243 & 3.12 & 4706 & 5812 & 30 & $16.8 \%$ \\
\hline & 0.01 & - & & 3577 & 1.96 & 4609 & 7576 & 39.1 & $52.3 \%$ \\
\hline
\end{tabular}

\subsection{Preparation of Nanofluids}

Nanofluids are prepared by adding dried NPs with different mass fractions into filtered and degassed Nytro 10XN mineral oil. The mineral oil has a mass density of $880 \mathrm{~kg} / \mathrm{m}^{3}$ and a relative electric permittivity of 2.2. In order to discuss the electron attachment hypothesis [5], the set of NPs chosen have associated relaxation time constants lower and higher than the microsecond time scales of the streamer development. Similarly, the NPs chosen range from highly hydrophilic to highly hydrophobic in order to discuss the water absorption hypothesis [16]. Five different NPs are used: laboratory-grade zinc oxide $\left(\mathrm{ZnO}^{-\mathrm{C}_{18}}\right)$ silane-coated NPs [21] and commercial-grade NPs of aluminum 
oxide $\left(\mathrm{Al}_{2} \mathrm{O}_{3}\right)$, titanium oxide $\left(\mathrm{TiO}_{2}\right)$, silicon oxide $\left(\mathrm{SiO}_{2}\right)$ and fullerene (buckminsterfullerene $\left.\mathrm{C}_{60}\right)$ distributed by IoLiTec. The size of the NPs is equal to or lower than $20 \mathrm{~nm}$, which is expected to lead to a stronger effect in the nanofluid compared with larger NPs (e.g., [2]). Their respective relaxation time constants, hydrophilicity, mass density $\rho_{m}$ and further parameters are reported on Table 1 . Since the additives and surfactants generally used to treat the surface of NPs may influence the physical and dielectric properties of nanofluids (e.g., [22]), they are not used here during the preparation of the nanofluids. In this way, changes in the streamer inception voltage of the prepared nanofluids can be attributed exclusively to the properties of the NPs.

The NPs are dispersed in the fluid by using an ultrasonic bath for $30 \mathrm{~min}$. Moisture content is not measured in these experiments, but an estimate of $10 \mathrm{ppm}$ is expected from previous work of the authors (e.g., [23]). In order to synthetize the nanofluids at low NP concentration, a large amount of liquid is first prepared and only a fraction is used in the experiments. After preparation, a sample of the used nanofluid is taken immediately for size distribution analysis while the streamer inception tests are performed. The aggregate size distribution of the nanofluids are measured at $25^{\circ} \mathrm{C}$ using dynamic light scattering (DLS) with a Malvern Zetasizer Nano ZS instrument. Even though nanofluids trend to agglomerate with time (e.g., [24]), the DLS measurements have shown that the used nanofluids are stable throughout the duration of the test. However, observe that the long-term stability of the used nanofluids has not been measured since it is outside the scope of this paper. The measured aggregates average sizes (AS) of the used NPs are also reported in Table 1.

\subsection{Streamer Testing Procedure}

The inception of streamers is measured under a voltage ramp $V_{R}$ obtained by charging a capacitor. The voltage $V_{R}$ follows the equation:

$$
V_{R}=12 \mathrm{kV}\left[1-\exp \left(-\frac{t}{3.2 \mu \mathrm{s}}\right)\right]
$$

The duration of the voltage ramp is $5 \mu \mathrm{s}$. Positive or negative streamers are incepted by applying the voltage ramp to the needle or to the sphere electrode, while the opposite electrode is connected to the ground.

It should be noted that the shape of the applied voltage differs from traditional voltages waveforms reported in the literature, such as AC $50 \mathrm{~Hz}$ [25], DC waveforms [26], lightning impulse [27] or rectangular waveforms [28]. The main reason for choosing a fast voltage ramp lies on the stability of the nanofluids. Nanoparticles dispersed on mineral oil can rapidly agglomerate and sediment, affecting the electrical behavior of the nanofluid. Therefore, the complete test duration should be as short as possible to avoid changes in the nanofluids properties. Since each applied voltage ramp provides an inception voltage value suitable for direct statistical sample analysis, sufficient datapoints can be generated within a short time. Observe that other voltage waveforms would require a significantly larger number of experiments in order to reach the same accuracy level since they require multi-level test methods.

The inception of streamers is identified by detecting their emission of light with a Hamamatsu R11540 photomultiplier placed $100 \mathrm{~mm}$ away from the electrodes. The experiments are performed under dark conditions in order to avoid any stray light reaching the photomultiplier. The streamer inception voltage $V_{i n c}$ is defined as the instantaneous voltage at the moment when the first light signal pulse is detected. A typical measurement of the applied voltage $V_{R}$, light signal and estimated $V_{\text {inc }}$ are shown in Figure 2.

The streamer inception voltage determined with this light detection method has been compared with that obtained using a charge measurement technique similar to that developed in [17]. Although both techniques lead to similar results (not shown here), the light detection technique is more sensitive since it can detect streamers with an electric charge lower than $0.05 \mathrm{pC}$. Therefore, the light detection technique is here preferred over a charge measurement due to its sensitivity, simplicity and reliability. 


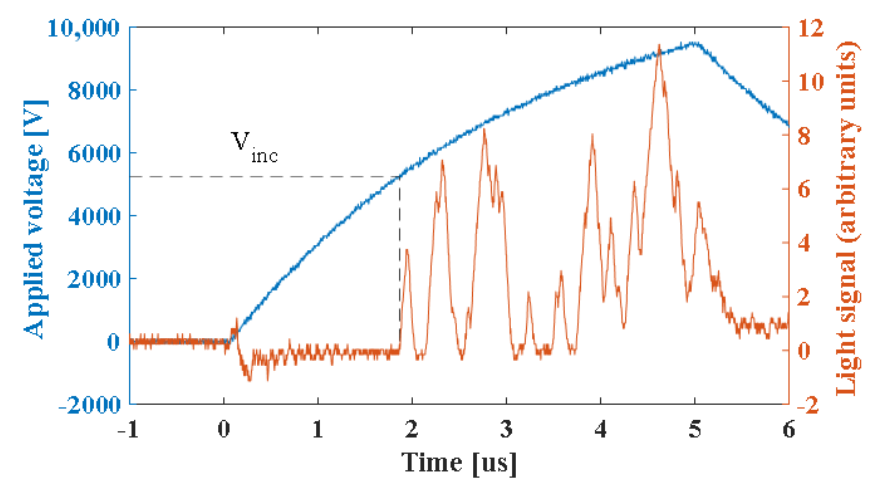

Figure 2. Typical applied voltage $V_{R}$ and light signal recorded as a function of time. The streamer inception voltage $V_{i n c}$ is also indicated.

For each nanofluid under each polarity, 200 voltage ramps are applied with a waiting time of three seconds in between them. $V_{i n c}$ is estimated for each voltage ramp, and used to build the empirical cumulative distribution function (CDF) of the test. The three-parameter Weibull function [29] used to fit the data follows the equation:

$$
F\left(V_{i n c}\right)=1-\exp \left(-\left(\frac{V_{i n c}-\gamma}{\eta}\right)^{\beta}\right), V_{i n c}>\gamma,
$$

where $\gamma, \eta$ and $\beta$ are the location, scale and shape parameters of the Weibull function, respectively. Table 1 shows the parameters in all tests estimated using the Weibull++ software. The streamer inception experiments for each nanofluid under each polarity are first performed in mineral oil in the absence of any NP. In this manner, the reference CDF of the base liquid is obtained. Then, nanofluids with different concentrations are prepared and immediately tested.

Since streamers (especially those of positive polarity) lead to a breakdown of the liquid soon after their inception is reached, an insulating solid barrier is generally used to electrically isolate one electrode. This prevents streamers from bridging the entire gap and damage the electrodes [30]. Two reasons prevented the use of an insulating solid in the experiments hereby reported. The first is that the insulating solid accumulates charge over repeated experiments leading to a reduction of the electric field and ultimately increasing the streamer inception voltage. In order to prevent charge accumulation, sufficiently long waiting times between experiments must be provided in order to allow the charges to dissipate. However, experiments with nanofluids require a short duration of the test in order to avoid agglomeration of the nanofluid as already mentioned. The second reason is the possible interaction of NPs with the solid interface, which introduces a further uncertainty that is difficult to assess.

In order to reduce the possibility of breakdown, a large gap distance is initially set for each needle-sphere configuration. The gap distance is then reduced until the $50 \%$ probability streamer inception voltage $V_{50 \%}$ of the $\mathrm{CDF}$ in mineral oil reaches values about half of the maximum applied voltage, at about $5 \mathrm{kV}$. This $V_{50 \%}$ in mineral oil is chosen in order to be able to measure increments of the $V_{50 \%}$ larger than $70 \%$ when nanofluids are tested under same electrode configuration. The gap distances set in the experiment are reported in Table 1.

The next step in the experiment is to measure the effect of the NPs on the $V_{50 \%}$ relative to that of the base oil. For this reason, the CDF obtained for each nanofluid is compared to its reference CDF previously measured in mineral oil under the same electrode configuration. In this manner, the effect of each kind of NP relative to mineral oil can be addressed despite of the different electrode configurations set throughout the experiment. Since the $V_{50 \%}$ of mineral oil is measured in all electrode configurations, it is also possible to perform a comparison of the Laplacian electric fields at the measured $V_{50 \%}$ between the different electrode configurations used. Results of this analysis are reported in Section 4.1. 


\section{Streamer Inception in Nanofluids}

\subsection{Silicon Oxide, Titanium Oxide and Aluminum Oxide Nanofluids}

Figure 3 shows the streamer inception probability curves obtained for the $\mathrm{SiO}_{2}$ nanofluids under both polarities and the corresponding reference with mineral oil. The three-parameter Weibull fitting curves for each dataset are depicted as solid lines whilst the data points are depicted with markers. Figure 4 shows changes in the $V_{50 \%}$ of $\mathrm{SiO}_{2}$ nanofluids relative to the mineral oil. Error bars correspond to the $95 \%$ confidence bounds of the estimated $V_{50 \%}$. No significant change on the negative streamer inception voltage is found within the tested concentrations in comparison with mineral oil. Likewise, no differences in the empirical distribution functions of the nanofluids and mineral oil under positive polarity are observed below a concentration threshold at about $0.005 \mathrm{wt} \%$. However, $\mathrm{SiO}_{2} \mathrm{NPs}_{\text {are }}$ found to have a significant impact on the $V_{50 \%}$ of positive streamers above this threshold, as shown in Figure 4.

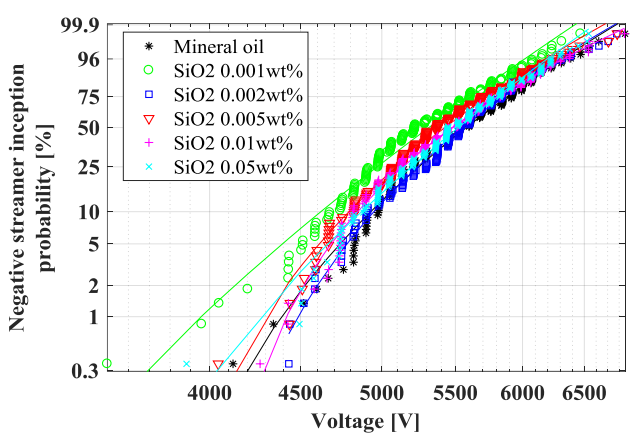

(a)

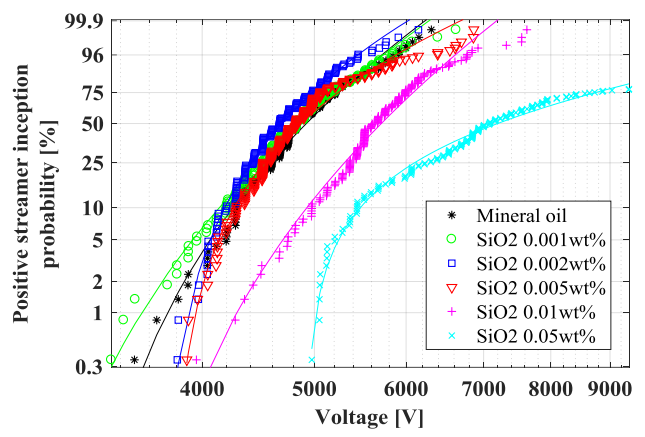

(b)

Figure 3. Streamer inception cumulative probability of $\mathrm{SiO}_{2}$ nanofluids at different mass concentrations under (a) negative and (b) positive polarity. The reference data of mineral oil is added for sake of comparison. The corresponding fitting Weibull functions are shown as solid lines.

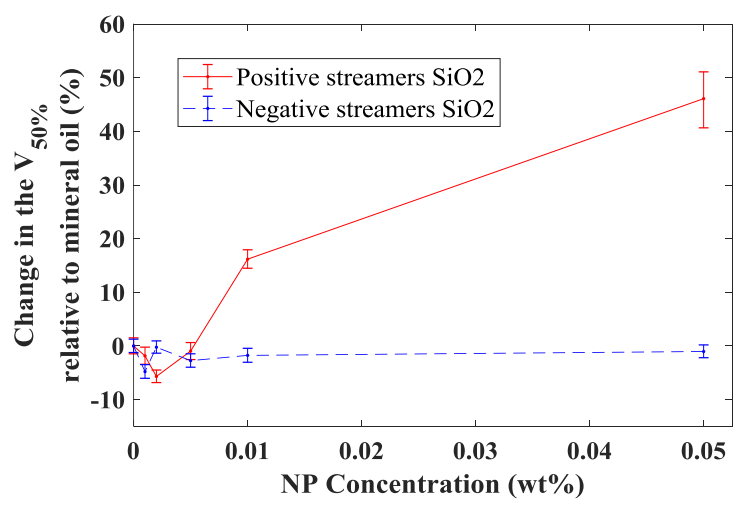

Figure 4. Change in $V_{50 \%}$ of $\mathrm{SiO}_{2}$ nanofluids relative to mineral oil as a function of mass fraction $w_{i}$.

The effect of $\mathrm{TiO}_{2}$ nanofluids on the streamer inception voltages is similar to that obtained with $\mathrm{SiO}_{2}$ nanofluids. Since there is no appreciable difference in the negative CFDs between mineral oil and $\mathrm{TiO}_{2}$ nanofluids, they are not shown. The CFDs for positive streamers in $\mathrm{TiO}_{2}$ nanofluids are shown in Figure 5 while the changes in $V_{50 \%}$ relative to mineral oil are depicted in Figure 6. Observe that the $V_{50 \%}$ of positive streamers increase with $\mathrm{TiO}_{2}$ concentration to similar values than those of $\mathrm{SiO}_{2}$ shown in Figure 4. However, the used concentrations of $\mathrm{TiO}_{2}$ are one order of magnitude lower than for the $\mathrm{SiO}_{2}$ nanofluid. No larger concentration of $\mathrm{TiO}_{2} \mathrm{NPs}$ is tested since the change in the $\mathrm{V}_{50 \%}$ of positive streamers already reaches a maximum level at the highest concentration used, as shown on Figure 6. 


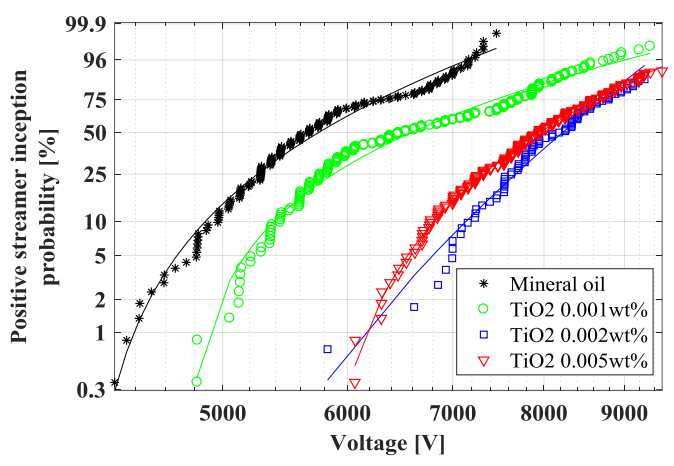

Figure 5. Streamer inception cumulative probability of $\mathrm{TiO}_{2}$ nanofluids at different mass concentrations under positive polarity. The reference data of mineral oil is added for sake of comparison. The corresponding fitting Weibull functions are shown as solid lines.

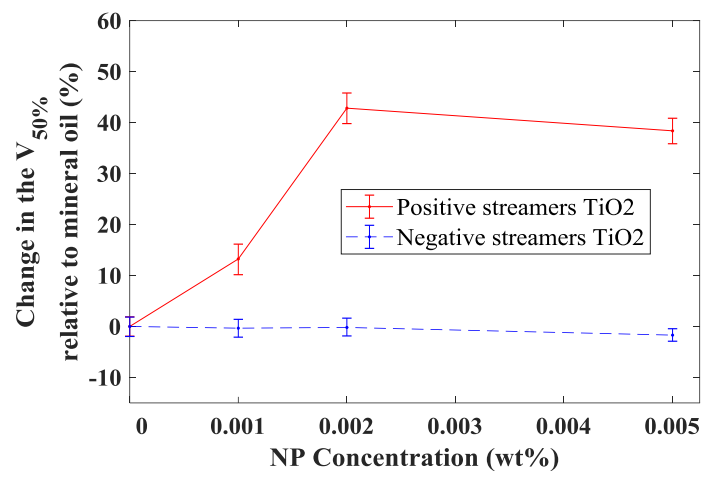

Figure 6. Change in $V_{50 \%}$ of $\mathrm{TiO}_{2}$ nanofluids relative to mineral oil as a function of mass fraction $w_{i}$.

Figure 7 depicts the $V_{50 \%}$ change of the $\mathrm{Al}_{2} \mathrm{O}_{3}$ nanofluids relative to mineral oil for streamers of both polarities as a function of concentration. It is found that $V_{50 \%}$ increases with concentration until a maximum peak value is reached at $w_{i} \sim 0.02 \mathrm{wt} \%$. A larger concentration yields in turn a lower $V_{50 \%}$ relative to that at $w_{i} \sim 0.02 \mathrm{wt} \%$. Although the CFDs are not shown, the estimated three parameters of the Weibull function for the curves are reported in Table 1.

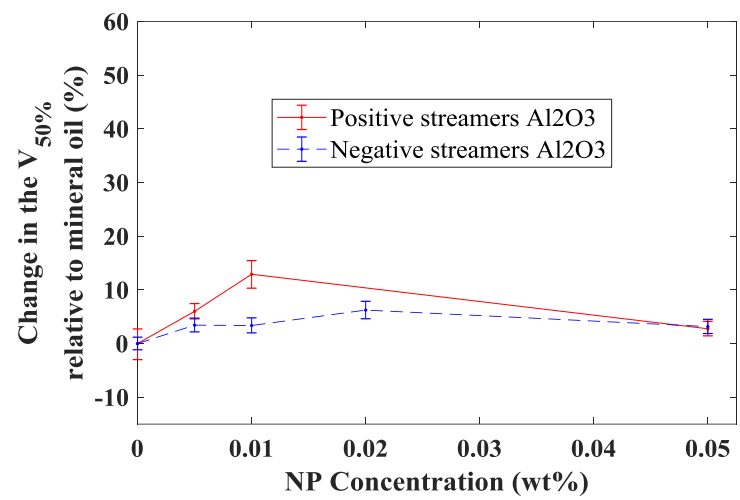

Figure 7. Change in $V_{50 \%}$ of $\mathrm{Al}_{2} \mathrm{O}_{3}$ nanofluids relative to mineral oil as a function of mass fraction $w_{i}$.

In the literature, partial discharge (PD) experiments with $\mathrm{SiO}_{2}$ nanofluids have been previously reported in a $20 \mathrm{~mm}$ gap needle-plane configuration under DC voltages [26]. It was observed that $\mathrm{SiO}_{2}$ nanofluids increase the positive PD inception voltage relative to mineral oil, and at the same time, exhibit no effect on the inception voltage of negative PDs [26]. Even though the PD results measured 
in [26] cannot be quantitatively compared with the $V_{50 \%}$ here presented (since the experimental and physical conditions are different), they interestingly show the same consistent effect of $\mathrm{SiO}_{2}$ nanofluids.

Streamer inception experiments with $\mathrm{TiO}_{2}$ have also been recently reported in a needle-sphere electrode configuration with tip radius of 50-70 $\mu \mathrm{m}$ and $25 \mathrm{~mm}$ gap distance according to IEC 60897 [6]. It was observed in [6] that a $\mathrm{TiO}_{2}$ nanofluid with concentration of $0.0227 \mathrm{wt} \%$ increases $V_{50 \%}$ for positive streamers by $13.5 \%$ relative to mineral oil. Observe that the reported results for positive streamers also show an increase in $V_{50} \%$ when adding $\mathrm{TiO}_{2} \mathrm{NPs}$. However, no direct comparison between the results in Figure 6 and in [6] can be done since they correspond to nanofluids with different concentrations and surface treatment procedures.

Breakdown voltage experiments with $\mathrm{Al}_{2} \mathrm{O}_{3}$ nanofluids have been previously reported in a needle-plane electrode configuration with gap distances lower than $0.3 \mathrm{~mm}$ [3]. It was observed that breakdown voltage of $\mathrm{Al}_{2} \mathrm{O}_{3}$ nanofluids at $w_{i} \approx 0.45 \mathrm{wt} \%$ mass fraction concentration was lower than the breakdown voltage of the base oil, and that the breakdown voltage decreased as $\mathrm{Al}_{2} \mathrm{O}_{3}$ concentration increased [3]. This concentration is almost one order of magnitude larger than the highest concentration used in the experiments hereby reported for $\mathrm{Al}_{2} \mathrm{O}_{3}$. Interestingly, the decreasing trend of $V_{50 \%}$ under both polarities presented in Figure 7 for $w_{i}>0.02 \mathrm{wt} \%$ suggests that the concentrations used in [3] were already deleterious to the dielectric strength of mineral oil.

\subsection{Zinc Oxide and $C_{60}$ Nanofluids}

Figures 8 and 9 show the streamer inception probabilities obtained for the $\mathrm{ZnO}$ and $\mathrm{C}_{60}$ nanofluids under both polarities and their corresponding reference with mineral oil. Observe that the $V_{50 \%}$ of the nanofluids in both polarities is larger than that of the base fluid.

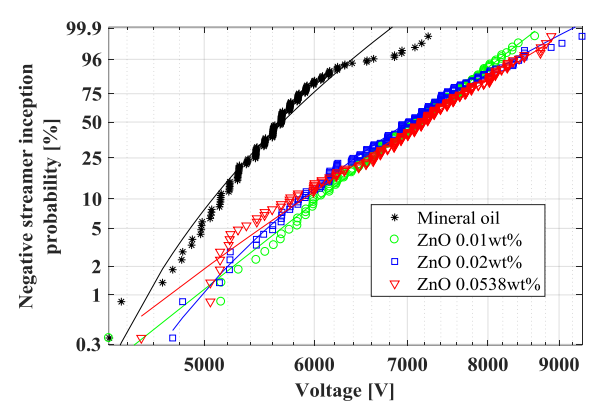

(a)

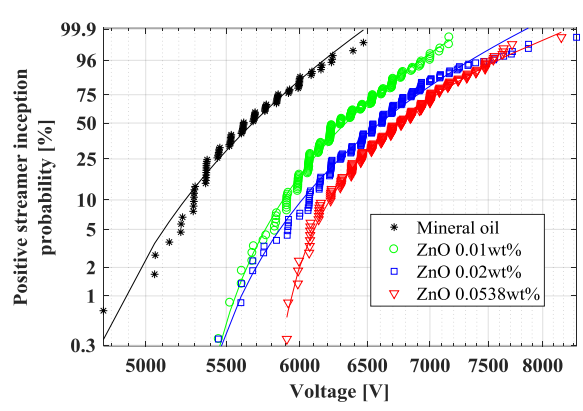

(b)

Figure 8. Streamer inception cumulative probability of $\mathrm{ZnO}$ nanofluids at different mass concentrations under (a) negative and (b) positive polarity. The reference data of mineral oil is added for sake of comparison. The corresponding fitting Weibull functions are shown as solid lines.

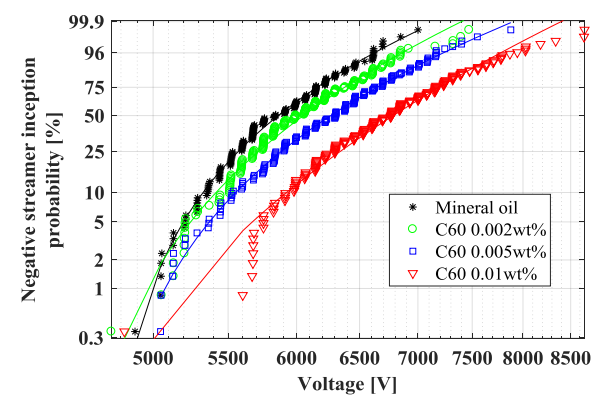

(a)

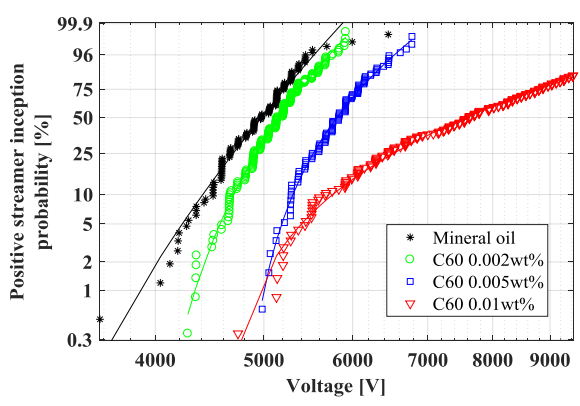

(b)

Figure 9. Streamer inception cumulative probability of $\mathrm{C}_{60}$ nanofluids at different mass concentrations under (a) negative and (b) positive polarity. The reference data of mineral oil is added for sake of comparison. The corresponding fitting Weibull functions are shown as solid lines. 
The change of the $V_{50 \%}$ of $\mathrm{ZnO}$ nanofluids relative to mineral oil as a function of NP concentration is depicted in Figure 10. As can be seen, $V_{50 \%}$ of the nanofluid under negative polarity is independent of the NPs concentration within the tested range. Even though small differences in $V_{50 \%}$ can be observed with concentration, they are attributed to the stochastic nature of the streamer inception process. On the other hand, the change on the $V_{50 \%}$ under positive polarity increase with NP concentration.

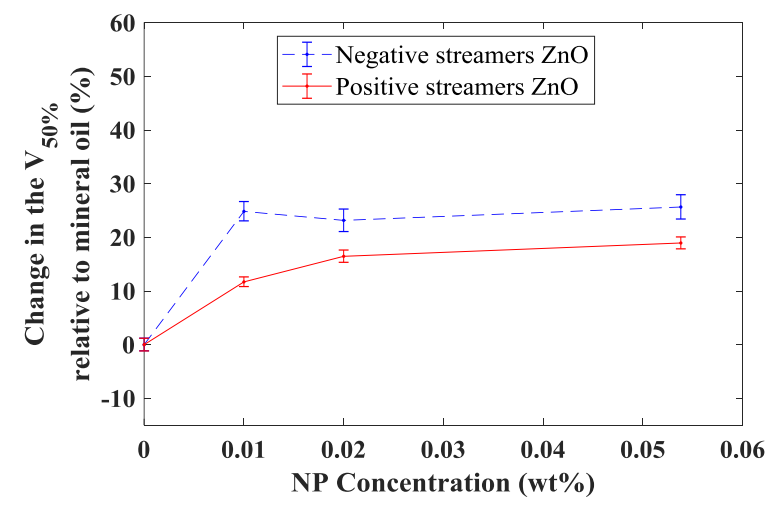

Figure 10. Change in $V_{50 \%}$ of $\mathrm{ZnO}$ nanofluids relative to mineral oil as a function of mass fraction $w_{i}$.

The changes in $V_{50 \%}$ of $\mathrm{C}_{60}$ nanofluids relative to mineral oil are depicted in Figure $11 . V_{50 \%}$ of both polarities for $\mathrm{C}_{60}$ nanofluids increase with concentration. Interestingly, $\mathrm{C}_{60}$ is the only NP among those here studied that monotonically increases $V_{50 \%}$ with concentration within the tested range. Concentrations of $\mathrm{C}_{60}$ are also lower than $\mathrm{ZnO}, \mathrm{Al}_{2} \mathrm{O}_{3}$ and $\mathrm{SiO}_{2} \mathrm{NPs}$, though yielding similar increments in the $V_{50 \%}$. This might be explained by the results presented in [2], where it was experimentally found that the dielectric strength of nanofluids improves with reductions of NPs size. The dielectric strength in [2] was measured according to ASTM D-877 on nanofluids prepared at concentrations below $0.5 \mathrm{wt} \%$ with NPs sizes lower than $100 \mathrm{~nm}$. In our case, Table 1 reports aggregates sizes lower than $1 \mathrm{~nm}$ for the tested $\mathrm{C}_{60}$ NPs in mineral oil, hence allowing these NPs to influence strongly the dielectric strength of the base oil at lower NP concentration.

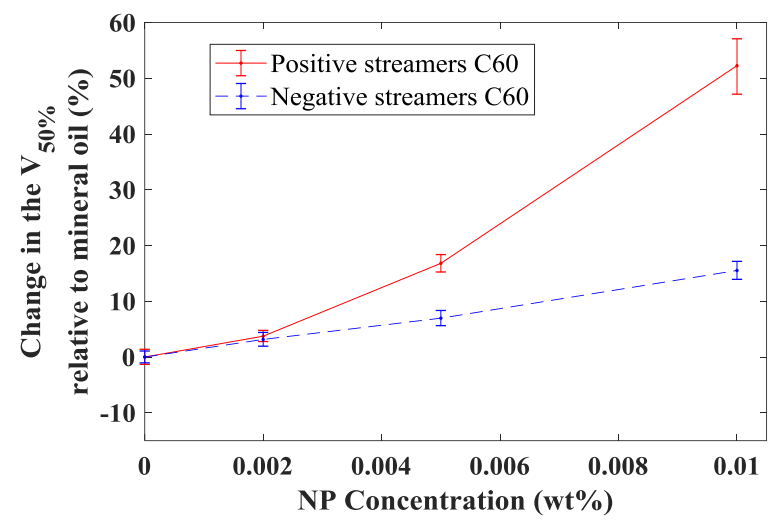

Figure 11. Change in $V_{50 \%}$ of $\mathrm{C}_{60}$ nanofluids relative to mineral oil as a function of mass fraction $w_{i}$.

PD inception experiments in $\mathrm{C}_{60}$ nanofluids at concentration of $0.01 \mathrm{wt} \%$ presented in [26] reported increments in positive and negative inception voltages of about $14 \%$ and $12 \%$ relative to the base oil, respectively. Since the inception voltages for PDs reported in [26] are not equivalent to the $V_{50 \%}$ here reported for streamers, they cannot be quantitatively compared. However, the results in [11] also show the consistent increase in the initiation voltage of prebreakdown phenomena in both polarities, as reported in Figure 11. 
Breakdown voltages in $\mathrm{ZnO}$ nanofluids have been also previously reported [2,4]. These improvements in breakdown voltage compared to the reference are consistent with the increment of the $V_{50 \%}$ of positive streamers relative to the base oil hereby presented.

\section{Discussion}

\subsection{Streamer Inception in Mineral Oil}

The evaluation of the streamer inception has been generally assessed in the literature based on the Laplacian electric field on the needle tip at $V_{50 \%}[11,30]$. In order to estimate the inception electric field $E_{L A P}$ in the experiments in mineral oil reported in the previous section, the Laplace equation $\nabla^{2} V=0$ is solved using COMSOL Multiphysics for the different needle-sphere electrodes used in the experiment. Boundary conditions are set accordingly to the applied voltage on each streamer polarity. The calculations are proven to be mesh independent.

The Laplacian fields $E_{L A P}$ for positive and negative streamers of the experiments performed in mineral are shown in Figure 12. It is found that $E_{L A P}$ increases as $R_{t i p}$ decreases and that $E_{L A P}$ of positive and negative streamers follow a similar trend. This finding is in good agreement with previously reported experiments in mineral oil with blunter needles [30]. However, the obtained values of $E_{L A P}$ here reported are up to two times larger than those obtained by extrapolation of the results in [30]. A possible explanation for this behavior lies on the electrostatic screening of the actual surface electric field due to the strong generation of charged carriers from ultra-sharp needles [20]. Observe that electric charges under the high electric fields in front of ultra-sharp needle tips are produced due to field emission, field ionization, or similar charge generation mechanisms, as previously studied by the authors $[20,23,31]$. As the produced charges accumulate in front of the needle's tip under the applied voltage ramp, the surface electric fields are electrostatically shielded. Since there is currently a lack of knowledge on the effect of the space charge on the streamer inception process, further analysis of these experiments can be the subject of future simulation studies.

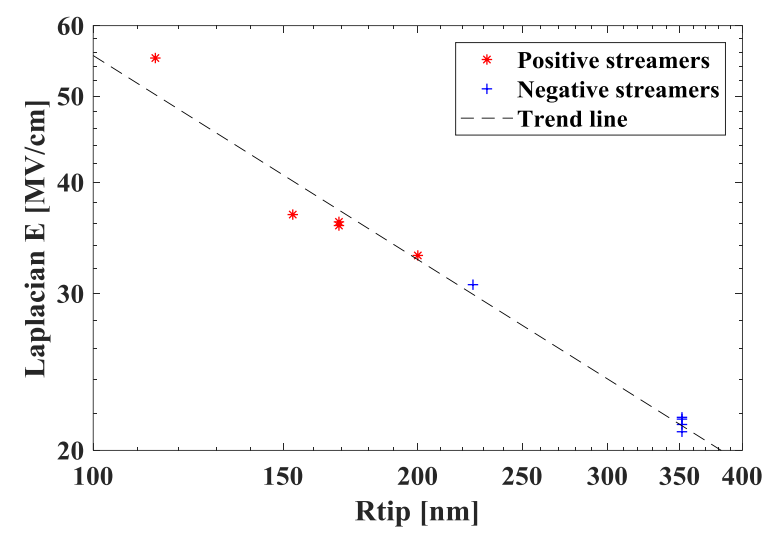

Figure 12. Laplacian electric field at the tip of the needles at $V_{50 \%}$ for mineral oil as a function of $R_{\text {tip }}$.

\subsection{Streamer Inception in Nanofluids}

The initiation of streamers from the ultra-sharp needles in nanofluids also takes place under intense generation of charges, as discussed for mineral oil in the previous subsection. This intense production of charged carriers defines a special precondition for the inception of streamers. Even though the existing hypotheses of the dielectric effect of NPs [8-10] were proposed for blunter electrodes (where charge generation before streamer initiation is less important [30]), they should still apply under the experimental conditions here reported. Thus, these hypotheses are discussed in this section. 


\subsubsection{Water Adsorption Hypothesis}

Increments in the positive partial discharge inception voltage reported in [26] were attributed to the moisture adsorption properties of the $\mathrm{SiO}_{2} \mathrm{NPs}$. This hypothesis was further strengthened by the fact that hydrophobic silane coated $\mathrm{SiO}_{2} \mathrm{NPs}$ yields deleterious effects on dielectric strength, whilst untreated $\mathrm{SiO}_{2} \mathrm{NPs}$ improve the dielectric strength [32].

Interestingly, the water adsorption hypothesis is consistent with the results here presented for $\mathrm{SiO}_{2}$ and $\mathrm{TiO}_{2}$ nanofluids. Both nanofluids exhibit increments on the positive streamer inception voltage and a negligible effect on the negative streamer inception voltage relative to the base oil, as observed in Figures 4 and 6 and reported in [26]. Furthermore, $\mathrm{TiO}_{2}$ exhibit superhydrophilicity when exposed to UV light [33]. The similar relative increments on $V_{50 \%}$ of positive streamers for $\mathrm{SiO}_{2}$ and $\mathrm{TiO}_{2}$ nanofluids measured with concentrations of $\mathrm{TiO}_{2}$ one order of magnitude lower than those of $\mathrm{SiO}_{2}$ indicate a greater water uptake capability of the $\mathrm{TiO}_{2} \mathrm{NPs}$, provided that the water adsorption hypothesis is the only mechanism for the improved positive streamer inception of $\mathrm{TiO}_{2}$ nanofluids.

On the other hand, $\mathrm{Al}_{2} \mathrm{O}_{3}$ NPs are hydrophilic by nature, but chemical reactions with carboxylic acids can render their surfaces from highly hydrophilic to highly hydrophobic [34]. Although Nytro $10 \mathrm{XN}$ is a complex combination of hydrocarbons, its low acid number $A N<0.01 \mathrm{mg} \mathrm{KOH} / \mathrm{L}$ suggests $\mathrm{Al}_{2} \mathrm{O}_{3} \mathrm{NPs}$ dispersed in oil are still hydrophilic. In comparison to $\mathrm{SiO}_{2}$ and $\mathrm{TiO}_{2}$ nanofluids, the case with $\mathrm{Al}_{2} \mathrm{O}_{3}$ NPs show lower increments in the $V_{50 \%}$ of positive streamers. This could be then explained if $\mathrm{Al}_{2} \mathrm{O}_{3} \mathrm{NPs}$ dispersed in mineral oil are less hydrophilic than $\mathrm{SiO}_{2}$ and $\mathrm{TiO}_{2} \mathrm{NPs}$.

Furthermore, since $\mathrm{C}_{60}$ and silane-coated $\mathrm{ZnO}$ NPs are hydrophobic [21,35], water adsorption cannot explain the increments in streamer inception voltages reported in Figures 10 and 11. These findings indicate that NPs influence the positive streamer inception process by other physical mechanism(s) in addition to water adsorption.

\subsubsection{Shallow Traps Hypothesis}

It was observed in [6] that there is an increment on the shallow trap density of $\mathrm{TiO}_{2}$ nanofluids relative to the base oil. It was then hypothesized that $\mathrm{TiO}_{2} \mathrm{NPs}$ increased the electron trapping and de-trapping processes, reducing the electron velocity in nanofluids relative to the base oil. However, it is generally accepted that negative streamers in liquids are initiated by electronic processes in the liquid phase $[10,11,36]$, which are influenced by the electron velocity and attachment processes. If $\mathrm{TiO}_{2}$ NPs would reduce the electron velocity, an effective reduction of the $V_{50} \%$ for negative streamers would also be expected. However, results on $\mathrm{TiO}_{2}$ here presented in Figure 6 show no changes in the $V_{50 \%}$ of negative streamers relative to the base oil, casting doubts about the validity of this hypothesis.

\subsubsection{Electron Attachment Hypothesis}

The electron attachment hypothesis of NPs is presented in [5]. It claims that NPs act as scavengers of electrons converting them into slower ions. The electron attachment process follows a charging relaxation time constant $\tau_{r}$ defined by:

$$
\tau_{r}=\frac{2 \epsilon_{1}+\epsilon_{2}}{2 \sigma_{1}+\sigma_{2}}
$$

where $\epsilon$ is the electrical permittivity and $\sigma$ is the electrical conductivity, with the subscript 1 for the host oil and 2 for the NPs. According to [5], this constant defines a criterion to estimate whether a $\mathrm{NP}$ can influence the streamer development. If $\tau_{r}$ is small compared to the time scale of streamer development, then the NP will relax fast enough and electrons will attach to it.

In the literature, this hypothesis has been claimed to disagree with the results presented in [3] where SiC nanofluids with a relaxation time constant of $\tau_{r} \approx 1$ ps yielded deleterious effects on the dielectric strength of the host oil. However, there are doubts whether the experimental sample preparation in [3] (including excessive moisture and size distribution of NPs) provides appropriate conditions to evaluate the effects of SiC NPs. On the other hand, the validity of the electron attachment 
hypothesis has also been questioned based on results presented in $[6,26]$. They report that $\mathrm{TiO}_{2}$ and $\mathrm{SiO}_{2}$ nanofluids improve the dielectric strength of the host liquid despite of their relatively large $\tau_{r}$. Nevertheless, it could be argued that water absorption of NPs is instead the main mechanism behind these reported improvements of $\mathrm{SiO}_{2}$ and $\mathrm{TiO}_{2}$ nanofluids, as already discussed in Section 4.2.1.

In order to revisit the validity of the electron attachment hypothesis only, it is here analyzed for negative streamer inception, which is not affected by moisture content. Interestingly, it is found that the changes in $V_{50} \%$ of negative streamers here reported for $\mathrm{SiO}_{2}, \mathrm{TiO}_{2}, \mathrm{Al}_{2} \mathrm{O}_{3}$ and $\mathrm{ZnO}$ are consistent with the relaxation time constant $\tau_{r}$ criterion. Thus, NPs with large $\tau_{r}$ do not have any appreciable effect on the $V_{50 \%}$ of negative streamers, while only the $\mathrm{ZnO}$ nanofluids with low $\tau_{r}$ improve the $V_{50 \%}$ of negative streamers even beyond the improvements perceived in the $V_{50 \%}$ of positive streamers, as shown in Figure 10. This result is consistent with the electron attachment hypothesis judged by the charging relaxation time constant $\tau_{r}$. Observe that the $\mathrm{C}_{60}$ NPs cannot be used for this analysis due to the broad range of variation of its electrical conductivity. Using the electrical conductivities of $\mathrm{C}_{60}$ NPs reported in the literature, ranging between $10^{-12} \mathrm{~S} / \mathrm{m}$ [37] and $1.7 \times 10^{-6} \mathrm{~S} / \mathrm{m}$ in [38] and [39], $\tau_{r}$ varies widely from less than one picosecond to several seconds.

\section{Conclusions}

Positive and negative streamer inception voltages are measured from ultra-sharp needles for $\mathrm{SiO}_{2}$, $\mathrm{TiO}_{2}, \mathrm{Al}_{2} \mathrm{O}_{3}$, surface modified $\mathrm{ZnO}$ and $\mathrm{C}_{60} \mathrm{NPs}$ dispersed in mineral oil at different mass fractions. It is found that NPs affect differently the inception of positive and negative streamers. While $\mathrm{SiO}_{2}$, $\mathrm{TiO}_{2}$ and $\mathrm{Al}_{2} \mathrm{O}_{3} \mathrm{NPs}$ improves the $50 \%$ probability inception voltage $\left(V_{50 \%}\right)$ of positive streamers, they do not influence the $V_{50 \%}$ of negative streamers. In turn, surface modified $\mathrm{ZnO}$ and $\mathrm{C}_{60} \mathrm{NPs}$ improve the $V_{50 \%}$ under both polarities.

It is found that the hypothesis that NPs absorb water as postulated in $[25,26]$ can explain the increments of the $V_{50 \%}$ of positive streamers for the hydrophilic $\mathrm{SiO}_{2}, \mathrm{TiO}_{2}$ and $\mathrm{Al}_{2} \mathrm{O}_{3} \mathrm{NPs}$. Therefore, the here-reported experimental results support the hypothesis that hydrophilic NPs increase the positive streamer inception voltage of the base oil. Since hydrophobic surface modified $\mathrm{ZnO}$ and $\mathrm{C}_{60}$ NPs also exhibit increments in the $V_{50}$ for positive streamers (relative to the host oil), it is concluded that other physical mechanism(s) should also be active.

On the other hand, the hypothesis that NPs increase the electron trapping and de-trapping processes in the liquid $[6,27,40]$ fails to explain the presented results. Negative streamers in liquids are incepted through electronic avalanches in the liquid phase $[10,11,36]$, and thus they should be influenced by the electronic properties of the liquid. Since results hereby reported show that $\mathrm{TiO}_{2}$ NPs do not influence the negative streamers, it cannot be claimed that $\mathrm{TiO}_{2} \mathrm{NPs}$ influence the electron velocity of the mineral oil. On the other hand, the $V_{50 \%}$ of negative streamers here reported for $\mathrm{SiO}_{2}$, $\mathrm{TiO}_{2}, \mathrm{Al}_{2} \mathrm{O}_{3}$, and $\mathrm{ZnO}$ nanofluids are consistent with the electron attachment hypothesis of NPs, judged through the relaxation time constant $\tau_{r}[5]$.

Author Contributions: Conceptualization, M.A. and M.B.; Data curation, M.A., M.B. and M.E.K.; Formal analysis, M.A., M.B. and M.E.K.; Funding acquisition, M.A. and M.B.; Investigation, M.A., M.B. and M.E.K.; Methodology, M.A. and M.B.; Project administration, M.B.; Resources, M.B.; Software, M.A.; Supervision, M.B.; Validation, M.A. and M.B.; Visualization, M.A.; Writing-Original Draft, M.A.; Writing-Review \& Editing, M.B. and M.E.K.

Funding: M.A. would like to thanks Colciencias for the funds received for this research. M.B. would like to acknowledge the financial support of the Swedish strategic research program StandUp for Energy.

Acknowledgments: The technical support of Janne Nilsson during the development of the set-up used in the experiments is highly appreciated.

Conflicts of Interest: The authors declare no conflict of interest. 


\section{References}

1. Segal, V.; Hjortsberg, A.; Rabinovich, A.; Nattrass, D.; Raj, K. AC (60 Hz) and impulse breakdown strength of a colloidal fluid based on transformer oil and magnetite nanoparticles. In Proceedings of the Conference Record of the 1998 IEEE International Symposium on Electrical Insulation, Arlington, VA, USA, 7-10 June 1998; Volume 2, pp. 619-622.

2. Katiyar, A.; Dhar, P.; Nandi, T.; Das, S.K. Effects of nanostructure permittivity and dimensions on the increased dielectric strength of nano insulating oils. Colloids Surf. A Physicochem. Eng. Asp. 2016, 509, 235-243. [CrossRef]

3. Chiesa, M.; Das, S.K. Experimental investigation of the dielectric and cooling performance of colloidal suspensions in insulating media. Colloids Surf. A Physicochem. Eng. Asp. 2009, 335, 88-97. [CrossRef]

4. Madavan, R.; Balaraman, S. Investigation on effects of different types of nanoparticles on critical parameters of nano-liquid insulation systems. J. Mol. Liq. 2017, 230, 437-444.

5. Hwang, J.G.; Zahn, M.; O'Sullivan, F.M.; Pettersson, L.A.A.; Hjortstam, O.; Liu, R. Effects of nanoparticle charging on streamer development in transformer oil-based nanofluids. J. Appl. Phys. 2010, 107, 014310. [CrossRef]

6. Zhou, Y.; Sui, S.; Li, J.; Ouyang, Z.; Lv, Y.; Li, C.; Lu, W. The effects of shallow traps on the positive streamer electrodynamics in transformer oil based nanofluids. J. Phys. D Appl. Phys. 2018, 51, 105304. [CrossRef]

7. Li, J.; Zhang, Z.; Zou, P.; Grzybowski, S.; Zahn, M. Preparation of a vegetable oil-based nanofluid and investigation of its breakdown and dielectric properties. IEEE Electr. Insul. Mag. 2012, 28, 43-50. [CrossRef]

8. Velasco, J.; Frascella, R.; Albarracín, R.; Burgos, J.; Dong, M.; Ren, M.; Yang, L. Comparison of positive streamers in liquid dielectrics with and without nanoparticles simulated with finite-element software. Energies 2018, 11, 361. [CrossRef]

9. Denat, A. High field conduction and prebreakdown phenomena in dielectric liquids. IEEE Trans. Dielectr. Electr. Insul. 2006, 13, 518-525. [CrossRef]

10. Andre, D. Conduction and breakdown initiation in dielectric liquids. In Proceedings of the 2011 IEEE International Conference on Dielectric Liquids, Trondheim, Norway, 26-30 June 2011; Volume 22, pp. 1-11.

11. Beroual, A. Pre-breakdown mechanisms in dielectric liquids and predicting models. In Proceedings of the 2016 IEEE Electrical Insulation Conference (EIC), Montreal, QC, Canada, 19-22 June 2016; pp. 117-128.

12. Hwang, J.G.; Zahn, M.; Pettersson, L.A.A. Mechanisms behind positive streamers and their distinct propagation modes in transformer oil. IEEE Trans. Dielectr. Electr. Insul. 2012, 19, 162-174. [CrossRef]

13. Ghassemi, M.; Cao, Y.; Chen, Q. A thermo-electrodynamic electric field dependent molecular ionization model to design electrical insulation system of HVDC wet-mate connectors under transient conditions. IEEE Trans. Dielectr. Electr. Insul. 2018, 25, 476-485. [CrossRef]

14. Naidis, G.V. Modelling of streamer propagation in hydrocarbon liquids in point-plane gaps. J. Phys. D Appl. Phys. 2015, 48, 195203. [CrossRef]

15. Lesaint, O. Prebreakdown phenomena in liquids: Propagation 'modes' and basic physical properties. J. Phys. D Appl. Phys. 2016, 49, 144001. [CrossRef]

16. Jin, H.; Andritsch, T.; Tsekmes, I.A.; Kochetov, R.; Morshuis, P.H.F.; Smit, J.J. Properties of mineral oil based silica nanofluids. IEEE Trans. Dielectr. Electr. Insul. 2014, 21, 1100-1108.

17. Liu, Z.; Liu, Q.; Wang, Z.D.; Jarman, P.; Krause, C.; Smith, P.W.R.; Gyore, A. Partial discharge behaviour of transformer liquids and the influence of moisture content. In Proceedings of the 2014 IEEE 18th International Conference on Dielectric Liquids (ICDL), Bled, Slovenia, 29 June-3 July 2014.

18. Yamashita, H.; Yamazawa, K.; Wang, Y.S. The effect of tip curvature on the prebreakdown streamer structure in cyclohexane. IEEE Trans. Dielectr. Electr. Insul. 1998, 5, 396-401. [CrossRef]

19. Dumitrescu, L.; Lesaint, O.; Bonifaci, N.; Denat, A.; Notingher, P. Study of streamer inception in cyclohexane with a sensitive charge measurement technique under impulse voltage. J. Electrostat. 2001, 53, 135-146. [CrossRef]

20. Pourrahimi, A.M.; Hoang, T.A.; Liu, D.; Pallon, L.K.H.; Gubanski, S.; Olsson, R.T.; Gedde, U.W.; Hedenqvist, M.S. Highly efficient interfaces in nanocomposites based on polyethylene and $\mathrm{ZnO}$ nano/hierarchical particles: A novel approach toward ultralow electrical conductivity insulations. Adv. Mater. 2016, 28, 8651-8657. [CrossRef] [PubMed] 
21. Li, J.; Du, B.; Wang, F.; Yao, W.; Yao, S. The effect of nanoparticle surfactant polarization on trapping depth of vegetable insulating oil-based nanofluids. Phys. Lett. A 2016, 380, 604-608. [CrossRef]

22. Aljure, M.; Becerra, M.; Pallon, L.K.H. Electrical conduction currents of a mineral oil-based nanofluid in needle-plane configuration. In Proceedings of the 2016 IEEE Conference on Electrical Insulation and Dielectric Phenomena (CEIDP), Toronto, ON, Canada, 16-19 October 2016; pp. 687-690.

23. Primo, V.A.; Garcia, B.; Albarracin, R. Improvement of transformer liquid insulation using nanodielectric fluids: A review. IEEE Electr. Insul. Mag. 2018, 34, 13-26. [CrossRef]

24. Jin, H.; Andritsch, T.; Morshuis, P.H.F.; Smit, J.J. AC breakdown voltage and viscosity of mineral oil based $\mathrm{SiO}_{2}$ nanofluids. In Proceedings of the 2012 Annual Report Conference on Electrical Insulation and Dielectric Phenomena, Montreal, QC, Canada, 14-17 October 2012; pp. 902-905.

25. Jin, H.; Morshuis, P.; Mor, A.R.; Smit, J.J.; Andritsch, T. Partial discharge behavior of mineral oil based nanofluids. IEEE Trans. Dielectr. Electr. Insul. 2015, 22, 2747-2753. [CrossRef]

26. Du, Y.; Lv, Y.; Li, C.; Chen, M.; Zhong, Y.; Zhou, J.; Li, X.; Zhou, Y. Effect of semiconductive nanoparticles on insulating performances of transformer oil. IEEE Trans. Dielectr. Electr. Insul. 2012, 19, 770-776.

27. Dung, N.V.; Høidalen, H.K.; Linhjell, D.; Lundgaard, L.E.; Unge, M. Effects of reduced pressure and additives on streamers in white oil in long point-plane gap. J. Phys. D Appl. Phys. 2013, 46, 255501. [CrossRef]

28. McCool, J.I. Using the Weibull Distribution; John Wiley \& Sons, Inc.: Hoboken, NJ, USA, 2012.

29. Lesaint, O.L.; Top, T.V. Streamer initiation in mineral oil. part I: Electrode surface effect under impulse voltage. IEEE Trans. Dielectr. Electr. Insul. 2002, 9, 84-91. [CrossRef]

30. Becerra, M.; Frid, H.; Vázquez, P.A. Self-consistent modeling of laminar electrohydrodynamic plumes from ultra-sharp needles in cyclohexane. Phys. Fluids 2017, 29, 123605. [CrossRef]

31. Becerra, M.; Frid, H. Electrohydrodynamic motion due to space-charge limited injection of charges in cyclohexane. In Proceedings of the 2014 IEEE 18th International Conference on Dielectric Liquids (ICDL), Bled, Slovenia, 29 June-3 July 2014.

32. Jin, H.; Morshuis, P.H.F.; Smit, J.J.; Andritsch, T. The effect of surface treatment of silica nanoparticles on the breakdown strength of mineral oil. In Proceedings of the 2014 IEEE 18th International Conference on Dielectric Liquids (ICDL), Bled, Slovenia, 29 June-3 July 2014.

33. Fujishima, A.; Rao, T.N.; Tryk, D.A. Titanium dioxide photocatalysis. J. Photochem. Photobiol. C Photochem. Rev. 2000, 1, 1-21. [CrossRef]

34. Al-Shatty, W.; Lord, A.M.; Alexander, S.; Barron, A.R. Tunable surface properties of aluminum oxide nanoparticles from highly hydrophobic to highly hydrophilic. ACS Omega 2017, 2, 2507-2514. [CrossRef]

35. Ma, X.; Wigington, B.; Bouchard, D. Fullerene $\mathrm{C}_{60}$ : Surface energy and interfacial interactions in aqueous systems. Langmuir 2010, 26, 11886-11893. [CrossRef] [PubMed]

36. Dung, N.V.; Hoidalen, H.K.; Linhjell, D.; Lundgaard, L.E.; Unge, M. Influence of impurities and additives on negative streamers in paraffinic model oil. IEEE Trans. Dielectr. Electr. Insul. 2013, 20, 876-886. [CrossRef]

37. Mort, J.; Machonkin, M.; Ziolo, R.; Huffman, D.R.; Ferguson, M.I. Temperature dependence of photoconductivity in buckminsterfullerene films. Appl. Phys. Lett. 1992, 60, 1735-1737. [CrossRef]

38. Wen, C.; Li, J.; Kitazawa, K.; Aida, T.; Honma, I.; Komiyama, H.; Yamada, K. Electrical conductivity of a pure $\mathrm{C}_{60}$ single crystal. Appl. Phys. Lett. 1992, 61, 2162-2163. [CrossRef]

39. Pevzner, B.; Hebard, A.F.; Dresselhaus, M.S. Role of molecular oxygen and other impurities in the electrical transportand dielectric properties of $\mathrm{C}_{60}$ films. Phys. Rev. B 1997, 55, 16439-16449. [CrossRef]

40. Zhou, Y.; Hu, J.; Dang, B.; He, J. Titanium oxide nanoparticle increases shallow traps to suppress space charge accumulation in polypropylene dielectrics. RSC Adv. 2016, 6, 48720-48727. [CrossRef]

(C) 2018 by the authors. Licensee MDPI, Basel, Switzerland. This article is an open access article distributed under the terms and conditions of the Creative Commons Attribution (CC BY) license (http://creativecommons.org/licenses/by/4.0/). 